\title{
Production and purification of hydrogen-methane mixtures utilized in internal combustion engines
}

\author{
M. C. Annesini ${ }^{1}$, R. Augelletti ${ }^{1}$, M. De Falco ${ }^{2}$, S. Frattari ${ }^{1}$, \\ F. Gironi ${ }^{1} \&$ M. A. Murmura ${ }^{1}$ \\ ${ }^{1}$ Department of Chemical Engineering Materials Environment, \\ Sapienza University of Rome, Italy \\ ${ }^{2}$ University Campus Biomedico of Rome, Italy
}

\begin{abstract}
Blends of hydrogen and methane (hythane) with $20-25 \%$ of $\mathrm{H}_{2}$ can be used in internal combustion engines in order to reduce the $\mathrm{CO}_{2}$ and unburned hydrocarbon emissions and greenhouse effect. In this paper we show that solar steam reforming of natural gas at $500-550^{\circ} \mathrm{C}$ is a suitable process to produce such a mixture, but the reformed gas must be purified to reduce the $\mathrm{CO}_{2}$ concentration to less than 3\%. To this aim, a first Pressure Swing Adsorption (PSA) unit, which uses activated carbon as adsorbent material, is proposed to remove carbon dioxide, with $\mathrm{H}_{2}$ and $\mathrm{CH}_{4}$ recovery of about 99 and 43\%, respectively; to enhance $\mathrm{CH}_{4}$ recovery, a second PSA unit, using carbon molecular sieve (CMS) as adsorbent, can be introduced. The whole suggested process produces an enriched methane mixture with a hydrogen content of $25 \%$, with an energy consumption of about $270 \mathrm{~kJ} / \mathrm{kg}$ of hydro-methane, mainly due to the electrical energy required for gas compression and vacuum pumps.

Keywords: hydrogen methane mixtures, solar steam reforming, pressure swing adsorption.
\end{abstract}

\section{Introduction}

Environmental problems due to the extensive use of fossil-derived energy in our societies are leading to devote research and innovation efforts to the study of novel technologies for de-carbonizing the fuels, thus reducing the carbon dioxide $\left(\mathrm{CO}_{2}\right)$ 
emissions and mitigating the GreenHouse effect. The most decarbonized fossil fuel is the methane, with a 75\% wt. of carbon and 25\% wt. of hydrogen which is extensively used in industrial and production processes. The end of the line of the energy decarbonation process is hydrogen itself, an energy vector which does not contain carbon and, consequently, does not produce $\mathrm{CO}_{2}$ during its combustion process [1,2]. Although many efforts and resources have been devoted to the development of solutions for hydrogen applications, the technology has not yet reached a proper level of competitiveness since many problems regarding production, storage, distribution and use have not been solved. Enriched methane (EM) constitutes an intermediate step toward decarbonation. EM is a mixture composed by $10-30 \%$ vol of hydrogen and methane, which means that the mixture is $26 \%-29 \%$ wt of $\mathrm{H}$ and $71 \%-74 \%$ of $\mathrm{C}$. The stoichiometric combustion of $1 \mathrm{~kg}$ of EM with $30 \%$ vol. $\mathrm{H}_{2}$ leads to the production of $2.61 \mathrm{~kg} \mathrm{CO}_{2}$, versus $2.75 \mathrm{~kg}$ emitted when burning pure $\mathrm{CH}_{4}$. Therefore, using EM instead of methane allows a reduction of distributed $\mathrm{CO}_{2}$ emissions by $5 \%$ approx. Unlike hydrogen, EM does not need specific solutions for distribution, storage and application, since, if the content of hydrogen is lower than $30 \% \mathrm{vol}$, the traditional natural gas technologies can be properly applied [3], so that EM can be immediately used by exploiting the already available Natural Gas (NG) infrastructures. One of the main applications of the blends of hydrogen and methane is in the field of sustainable mobility, since EM can be efficiently burned in NG Internal Combustion Engines. As attested in the literature [4], increasing hydrogen content in the NG engine allows the reduction of unburned hydrocarbons and carbon monoxide and the reduction of the overall production of $\mathrm{CO}_{2}$ as the EM stoichiometric carbon dioxide emission is lower. Furthermore, the use of EM increases the engine efficiency (1-3\%), so reducing specific fuel consumption. On the other hand, due to the higher flame temperature, an increase of NOx emissions could occur and an efficient catalytic converter may be required. Some papers dealing with the optimization of hydrogen percentage in EM fuel [5] reported that a hydrogen content in the blend of 20$25 \%$ vol may be utilized for optimizing the engine conversion efficiency. In this framework, the solar-driven steam reforming of natural gas at low temperature $\left(500-550^{\circ} \mathrm{C}\right)[6]$ appears as a very interesting process to produce the amount of hydrogen needed by the EM blend.

Unfortunately, the process produces also one mole of carbon dioxide per mole of reacted methane: this means that the mixture obtained from steam reforming has a $\mathrm{CO}_{2}$ percentage too high to be used as fuel in an internal combustion engine, so that the carbon dioxide has to be removed to obtain a $\mathrm{CO}_{2}$ content lower than $3 \%$. Obviously, a separation process able to operate with high recoveries of hydrogen and methane and low energy consumption is desirable. In this work the separation will be carried out by means of a double stage pressure swing adsorption process (PSA), the first one for the $\mathrm{CO}_{2}$ removal and the second one for the recovery of $\mathrm{CH}_{4}$. To demonstrate the technological feasibility and assess its performance, simulations have been carried out by feeding the PSA with a stream obtained from solar steam reforming of natural gas at $500-550^{\circ} \mathrm{C}$ and results are assessed and discussed. 


\section{The reforming process}

The methane steam reforming (MSR) process is the most used massive hydrogen production route and is based on following reactions

$$
\begin{array}{cc}
\mathrm{CH}_{4}+\mathrm{H}_{2} \mathrm{O} \rightleftarrows \mathrm{CO}+3 \mathrm{H}_{2} & \Delta H_{298 K}^{0}=206 \mathrm{~kJ} / \mathrm{mol} \\
\mathrm{CO}+\mathrm{H}_{2} \mathrm{O} \rightleftarrows \mathrm{CO}_{2}+\mathrm{H}_{2} & \Delta H_{298 K}^{0}=-41 \mathrm{~kJ} / \mathrm{mole}
\end{array}
$$

which together yield

$$
\mathrm{CH}_{4}+2 \mathrm{H}_{2} \mathrm{O} \rightleftarrows \mathrm{CO}_{2}+4 \mathrm{H}_{2} \quad \Delta H_{298 K}^{0}=165 \mathrm{~kJ} / \mathrm{mole}
$$

The reactions are very fast on nickel based catalysts and conditions near to the equilibrium are easily reached. Since the global process is highly endothermic, operating temperature in the range $850-950^{\circ} \mathrm{C}$ have to be used to obtain high conversions. On the other hand, if the aim of the process is to produce EM blend, a low methane conversion is acceptable and the process can operate at a lower temperature, thus allowing the coupling of MSR with solar powered technologies, such as the molten salt based concentrating solar plant. In this way the reforming process becomes environmentally friendly and requires only renewable energy.

For a quantitative evaluation of the performances of the process, the equilibrium conditions for reactions (1) and (2) can be easily obtained from thermodynamic data. Fig. 1 reports the hydrogen-to-methane ratio as a function of temperature and pressure for a natural gas feed $\left(97 \% \mathrm{CH}_{4}\right.$ and $\left.\mathrm{CO}_{2} 3 \%\right)$ with a steam to carbon ratio equal to 3 ; fig. 2 reports the carbon dioxide concentration obtained in the reformed gas after water separation. The figures show that the required $\mathrm{H}_{2} / \mathrm{CH}_{4}$ ratio can be theoretically obtained even when operating at very low temperatures (near $400^{\circ} \mathrm{C}$ ); in order to enhance the reaction kinetics, a higher temperature is suggested. In this work we consider a temperature in the range $500-550^{\circ} \mathrm{C}$ : this temperature can be easily obtained with a concentrating solar plant; furthermore efficient catalyst are suitable for the production a mixture with hydrogen content up to $30 \%$ even operating at high pressure in order to reduce the reactor size. On the other hand, the reforming reaction produces about one mole of carbon dioxide per mole of reacted methane: therefore, as shown in fig. 2, a $\mathrm{CO}_{2}$ content greater than $13 \%$ is obtained in the reformed gas. Indeed this content is too high for an automotive fuel and a separation process is required to reduce the $\mathrm{CO}_{2}$ content up to $3 \%$. In this paper, we consider the purification of a reformed gas obtained from a molten-salt heated reactor operating in the range $500-517^{\circ} \mathrm{C}$, with a steam to carbon ratio 3; according to the kinetic model previously published [7] the gas composition on the water free basis is $\mathrm{CH}_{4}=48 \%, \mathrm{CO}_{2}=12 \%$ and $\mathrm{H}_{2}=40 \%$ by volume, while the flow rate is adjusted to produce, after all the separation steps required, about $350 \mathrm{~kg} / \mathrm{h}$ of enriched methane. 


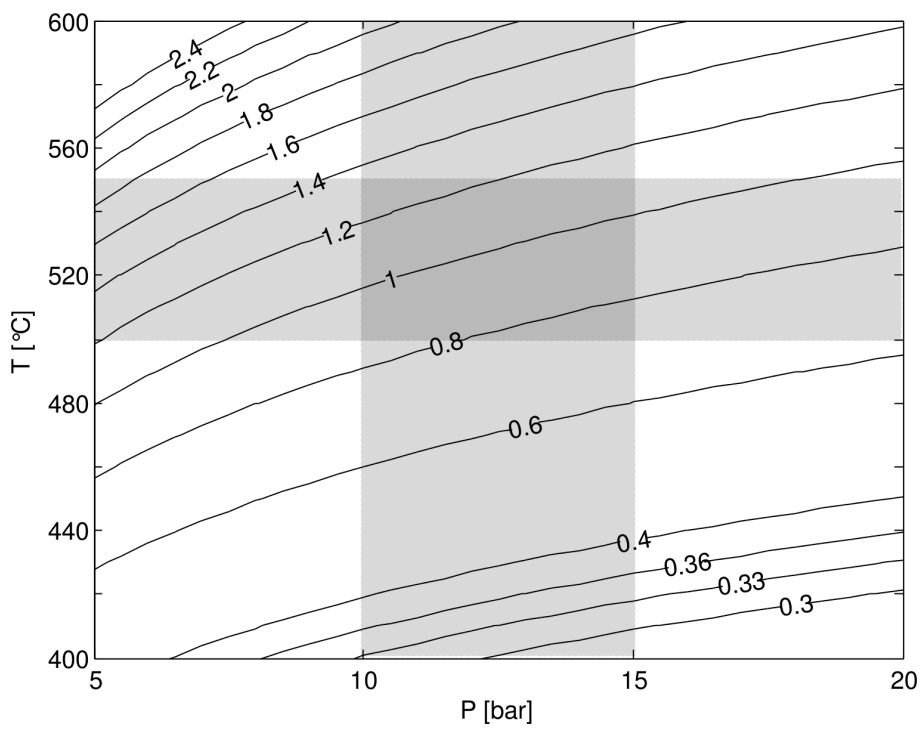

Figure 1: Hydrogen-to-methane ratio in the reformed gas as function of temperature and pressure. Feed: natural gas mixture $\left(97 \% \mathrm{CH}_{4}, 3 \% \mathrm{H}_{2}\right)$ steam-to-carbon ratio 3.

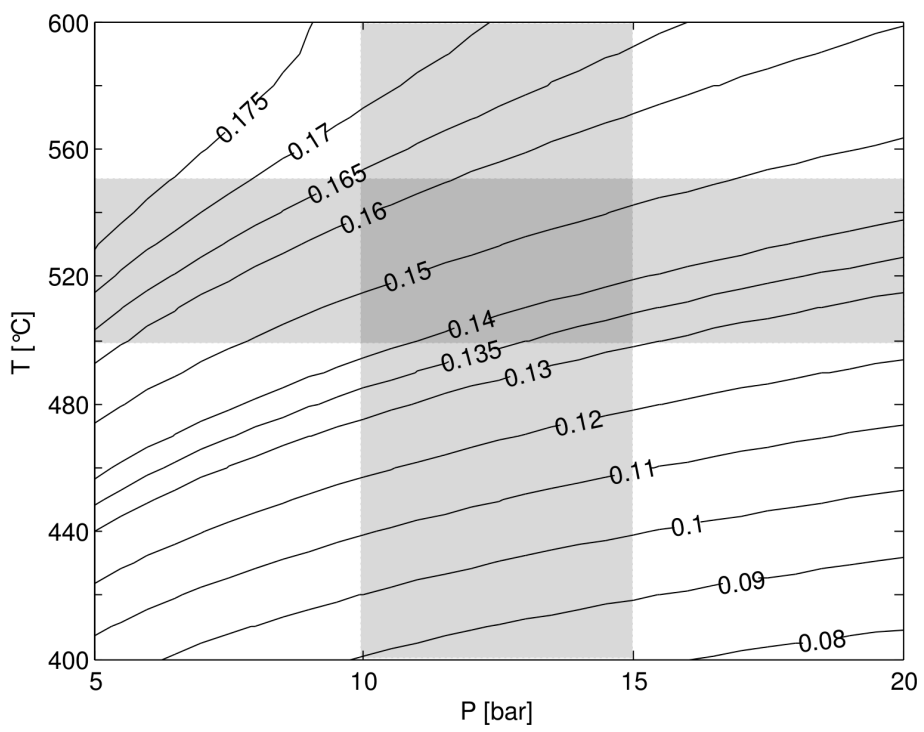

Figure 2: Carbon dioxide content in the reformed gas as function of temperature and pressure. Feed: natural gas mixture $\left(97 \% \mathrm{CH}_{4}, 3 \% \mathrm{H}_{2}\right)$ steam-tocarbon ratio 3 . 


\section{Pressure swing adsorption for reformed gas purification}

A very selective process to remove carbon dioxide is chemical absorption with amine solutions; this process is continuous, therefore plant design and operation are quite simple. The drawback of this process lies in the energy consumption due to the high temperature of the regeneration of amine solution; furthermore, these solvents are toxic, corrosive, and hazardous substances. Therefore this process does not seem to be suitable for small installations. Pressure Swing Adsorption (PSA) has attracted increasing interest because of its low energy requirements and investment costs. In a PSA unit, an adsorbent material is subjected to pressure changes to selectively adsorb and desorb the undesired gas components; the process operates near ambient temperature, without any need of thermal regeneration. In its basic configuration pressure swing adsorption has four steps (adsorption, blow-down, purge and pressurization) of equal or different time duration, implemented in two or more columns in order to make the gas treatment continuous. Many combinations of the cyclic adsorption, desorption, and complementary steps and their operating conditions in conjunction with a variety of adsorbents can be utilized to obtain the desired separation goals. A realistic simulation model is useful to evaluate the process performances in terms of purity, recovery and energy requirement, and then for screening between different adsorbent materials and process cycle or scheduling.In this work a dynamic literature non-isothermal model is used [8]. This model is based on the linear driving force approximation for the adsorption/desorption kinetics with a single lumped transport parameter for each component, $k_{L D F}$; thermal equilibrium between gas and solid phase and no heat exchange with the external environment are assumed; further details on the mathematical model are reported in the original paper [9].

We consider the design of a PSA process to treat a three component mixture (the reformed gas above reported) to reduce its carbon dioxide content to less than $3 \%$ and to obtain a high recoveries for both hydrogen and methane. As a first step, we design a four-column PSA unit, using activated carbon as adsorbent materials. Adsorption equilibrium is described by multicomponent Langmuir adsorption isotherm:

$$
\frac{q_{i}}{q_{\max , i}}=\frac{b_{i} p_{i}}{1+\sum_{j} b_{j} p_{j}}
$$

where $q_{i}$ and $p_{i}$ are the adsorbed amount and the partial pressure of each component and $q_{\max , i}$ and $b_{i}$ are temperature dependent parameters

$$
q_{\max , i}=k_{1 i}+k_{2 i} T \quad b_{i}=k_{3 i} \exp \left(-k_{4 i} / T\right)
$$

Adsorption isotherm parameters and kinetic parameters for $\mathrm{CO}_{2}, \mathrm{H}_{2}$ and $\mathrm{CH}_{4}$ adsorption onto activated carbon are reported in table 1 .

The PSA working cycle, reported in fig. 3, includes a) a feed (adsorption) step where the gas is fed to the column at high pressure (13 bar); a low- $\mathrm{CO}_{2}$ content gas is obtained form the column; b) an equalization step, where the high pressure 
Table 1: Equilibrium and kinetic parameter of activated carbon [10] and carbon molecular sieve [11] $\left(k_{1} \mathrm{~mol} / \mathrm{kg}, k_{2} \mathrm{~mol} / \mathrm{kgK}, k_{3} \mathrm{bar}^{-1} k_{4} \mathrm{~K}\right.$, $\Delta H_{a d s} \mathrm{kcal} / \mathrm{mol}, k_{L D F} \mathrm{~s}^{-1}$.

\begin{tabular}{cccccccc}
\hline & \multicolumn{3}{c}{ Activated carbon } & & \multicolumn{2}{c}{$\mathrm{CMS}$} \\
& $\mathrm{CO}_{2}$ & $\mathrm{CH}_{4}$ & $\mathrm{H}_{2}$ & & $\mathrm{CO}_{2}$ & $\mathrm{CH}_{4}$ \\
\hline$k_{1}$ & 28.80 & 23.86 & 16.94 & & 2.88 & 1.76 \\
$k_{2}$ & -0.07 & -0.056 & -0.021 & & 0 & 0 \\
$k_{3}$ & $1 \cdot 10^{-2}$ & $3.5 \cdot 10^{-3}$ & $6.2 \cdot 10^{-5}$ & & $2.4 \cdot 10^{-2}$ & $6.3 \cdot 10^{-4}$ \\
$k_{4}$ & 1030 & 1159 & 1229 & & 1312 & 2046 \\
$\Delta H_{a d s}$ & 1.25 & 1.02 & 0.54 & & 2.61 & 4.10 \\
$k_{L D F}$ & 0.036 & 0.195 & 0.700 & & 0.013 & $7.5 \cdot 10^{-5}$ \\
\hline
\end{tabular}

\begin{tabular}{|l|l|l|l|l|l|l|l|l|l|l|}
\hline Bed 1 & \multicolumn{2}{|c|}{ FE } & EQ & RIC & BD & \multicolumn{2}{|c|}{ PU } & EQ & \multicolumn{2}{c|}{ PR } \\
\hline Bed 2 & EQ & PR & \multicolumn{2}{|c|}{ PR } & FE & EQ & RIC & BD & \multicolumn{2}{|c|}{ PU } \\
\hline Bed 3 & \multicolumn{2}{|c|}{ PU } & EQ & PR & \multicolumn{3}{|c|}{ FE } & EQ & RIC & BD \\
\hline Bed 4 & EQ & RIC & BD & & PU & EQ & PR & \multicolumn{2}{|c|}{ FE } \\
\hline
\end{tabular}

Figure 3: Scheduling of four-column PSA cycle for $\mathrm{CO}_{2}$ removal. FE: feed, EQ: equalization, RIC: recycle, BD: blow-down, PU: purge, PR: pressurization.

gas present in the interstitial spaces of the column at the end of the feed phase is used to partially pressurize another column; c) a recycling step, where the gas still present in the column is compressed and used to further pressurize a different column; d) a blow-down step when the column is depressurized until vacuum conditions ( 0.1 bar) are reached, in order to remove the adsorbed carbon dioxide; e) a purge step, where the column is fed with the reformed gas at low pressure, in order to complete the adsorbent bed regeneration $\mathrm{f}$ ) an equalization step where the column is partially pressurized with the high pressure gas withdrawn from an other column; g) a pressurization step where the column is pressurized, firstly with a recycled stream, and subsequently with the reformed gas. The pressure profile in the cycle is reported in fig. 4; in the same figure, we also report the flow rates of different components at the top and bottom of the adsorption column.

The energy requirement, mainly due to the vacuum conditions reached in the blowdown and purge steps, is about $1700 \mathrm{~kJ} / \mathrm{kg}$ of produced hydrogen. The process allows to obtain a gas with less than $3 \%$ of $\mathrm{CO}_{2}$ and an almost complete hydrogen recovery; unfortunately, the off-gas has still a high methane content and, as a consequence, the methane recovery is low (see table 3 ). If a high methane recovery is desired, a second PSA unit can be added to separate the methane-carbon dioxide mixture. In this work we studied this second option. In this PSA unit, 

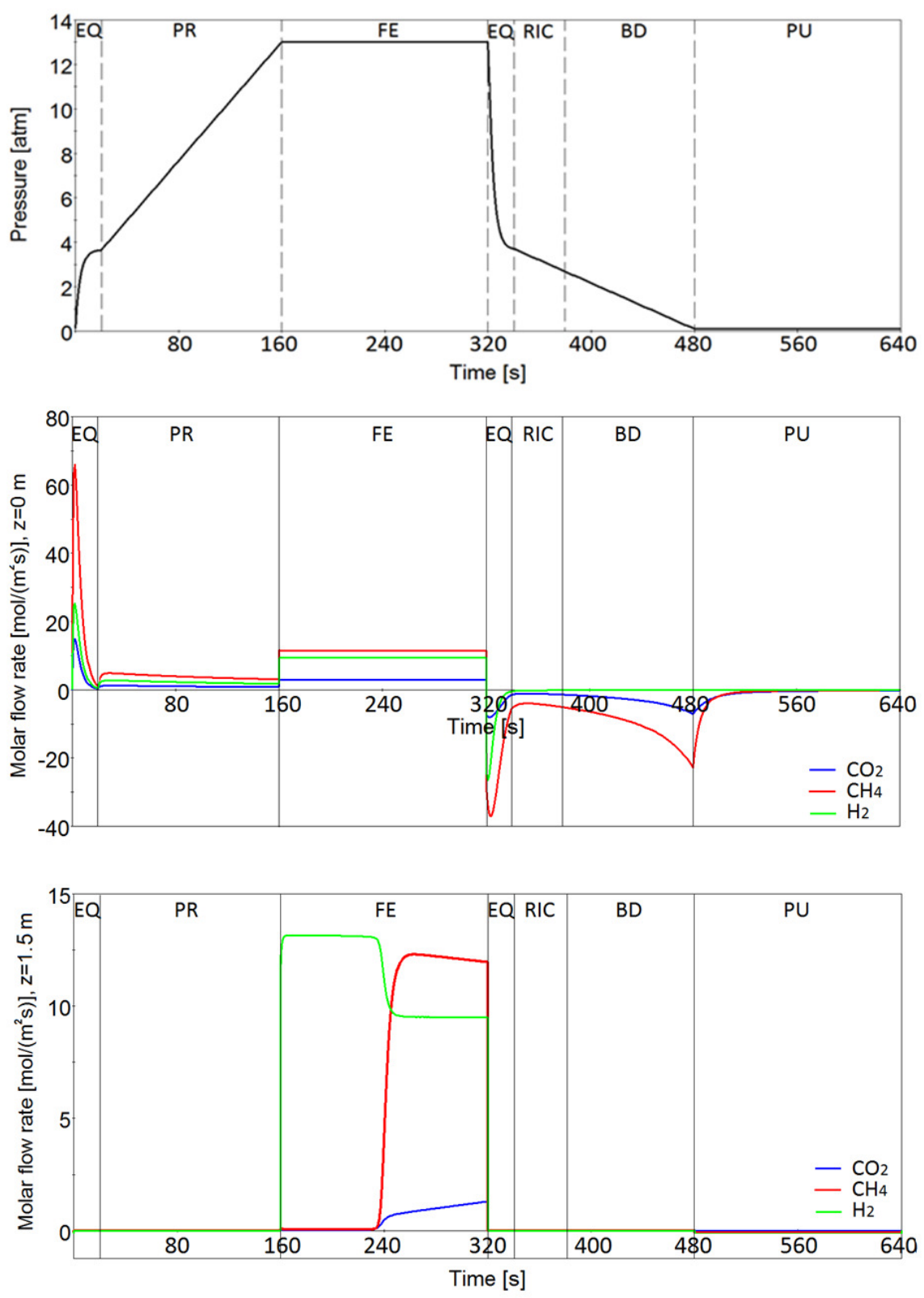

Figure 4: Pressure profile and flow rates in different steps of the PSA cycle for $\mathrm{CO}_{2}$ removal (column size in table 2). 
Table 2: Column characteristics and pressure operating conditions of PSA columns.

\begin{tabular}{cccc}
\hline & & Activated carbon & CMS \\
\hline column length & $\mathrm{m}$ & 1.5 & 1.8 \\
column diameter & $\mathrm{m}$ & 0.44 & 0.5 \\
column density & $\mathrm{kg} \mathrm{m}^{-3}$ & 482 & 695 \\
column porosity & - & 0.43 & 0.41 \\
pressure feed & bar & 13 & 4 \\
pressure purge & bar & 0.1 & 0.1 \\
\hline
\end{tabular}

Table 3: Performances of the activated carbon - PSA unit for $\mathrm{CO}_{2}$ removal.

\begin{tabular}{ccccccc}
\hline & \multicolumn{3}{c}{ Composition } & & \multicolumn{2}{c}{ Recovery } \\
& Feed & Product & Off-gas & & Product & Off-gas \\
\cline { 2 - 4 } \cline { 6 - 7 } $\mathrm{CH}_{4}$ & $48 \%$ & $33.7 \%$ & $71.9 \%$ & & $43.1 \%$ & - \\
$\mathrm{CO}_{2}$ & $12 \%$ & $2.8 \%$ & $26.6 \%$ & & - & $85.4 \%$ \\
$\mathrm{H}_{2}$ & $40 \%$ & 63.5 & $1.5 \%$ & & $98.6 \%$ & - \\
\hline
\end{tabular}

activated carbon is not an adequate adsorbent due to the low selectivity between methane and carbon dioxide. Higher selectivity, mainly related to differences in the adsorption kinetics, is obtained with carbon molecular sieves (CMS). Here we refer to a CMS with the properties reported in table 1; since the hydrogen concentration is very low, simulation is carried out considering a two-component $\left(\mathrm{CH}_{4}\right.$ and $\left.\mathrm{CO}_{2}\right)$ mixture. With this adsorbent, a classical five step cycle, including pressurization, feed, equalization, blow-down and purge steps is able to produce the desired performances. In details, the pressure profile and the flow rates of different components at the top and bottom of the adsorption column, are reported in fig. 5. The gas produced from this unit contains more $95.1 \%$ vol of $\mathrm{CH}_{4} .2 .7 \%$ of $\mathrm{CO}_{2}$ and $2.2 \%$ of $\mathrm{H}_{2}$; the off gas flow rate is quite low with a $\mathrm{CH}_{4}$ content of about $25 \%$; the methane recovery is greater than $88 \%$. The methane content in offgas allows this stream to be burned without external fuel. The energy requirement is about $1200 \mathrm{~kJ} / \mathrm{kg}$ of recovered methane.

The overall process scheme is reported in fig. 6, together with the mass balances and the operating conditions. It is worth noting that a blending of the produced gas with natural gas is considered in order to obtain the optimal hydroged-to-methane ratio in the enriched methane stream. 

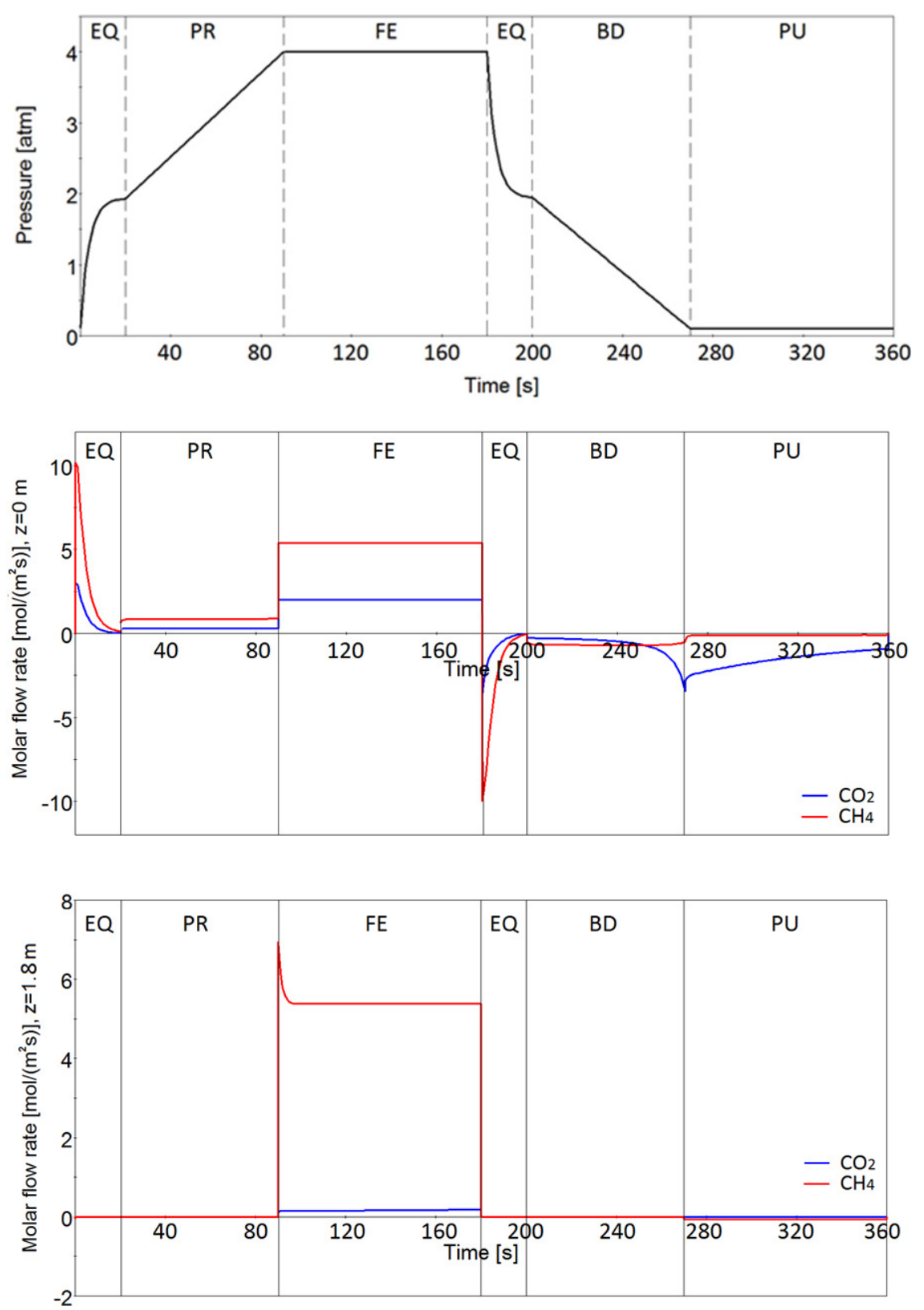

Figure 5: Pressure profile and flow rates in different steps of the PSA cycle for $\mathrm{CH}_{4}$ recovery (column size in table 2). 


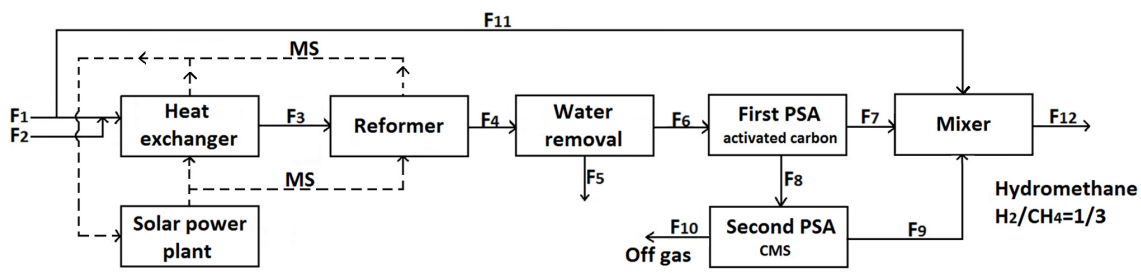

\begin{tabular}{|c|c|c|c|c|c|c|c|c|}
\hline & \multicolumn{2}{|c|}{ Flow rate } & \multicolumn{4}{|c|}{ Composition, $\%$} & \multirow{2}{*}{$\begin{array}{c}\mathrm{T} \\
{ }^{\circ} \mathrm{C} \\
\end{array}$} & \multirow{2}{*}{$\begin{array}{c}\mathrm{P} \\
\mathrm{atm}\end{array}$} \\
\hline & $\mathrm{kg} / \mathrm{h}$ & $\mathrm{Nm}^{3} / \mathrm{h}$ & $\mathrm{CH}_{4}$ & $\mathrm{CO}_{2}$ & $\mathrm{H}_{2}$ & $\mathrm{H}_{2} \mathrm{O}$ & & \\
\hline $\mathrm{F}_{1}$ & 157.8 & 210 & 97 & 3 & - & - & 25 & 15 \\
\hline $\mathrm{F}_{2}$ & 490.7 & 611 & - & - & - & 100 & 25 & 15 \\
\hline $\mathrm{F}_{3}$ & 648.5 & 821.1 & 24.8 & 0.8 & - & 74.4 & 500 & 15 \\
\hline $\mathrm{F}_{4}$ & 648.5 & 891.6 & 18.9 & 4.6 & 15.6 & 60.9 & 514 & 14.5 \\
\hline $\mathrm{F}_{5}$ & 435.8 & 542.7 & - & - & - & 100 & 50 & 13 \\
\hline $\mathrm{F}_{6}$ & 212.7 & 348.9 & 48 & 12 & 40 & - & 25 & 13 \\
\hline $\mathrm{F}_{7}$ & 75.8 & 215.7 & 33.7 & 2.8 & 63.5 & - & 25 & 13 \\
\hline $\mathrm{F}_{8}$ & 136.8 & 133.2 & 71.9 & 26.6 & 1.5 & - & 25 & 1 \\
\hline $\mathrm{F}_{9}$ & 65.5 & 89.2 & 95.1 & 2.7 & 2.2 & - & 25 & 13 \\
\hline $\mathrm{F}_{10}$ & 72.7 & 42.1 & 25 & 75 & - & - & 25 & 1 \\
\hline $\mathrm{F}_{11}$ & 200.8 & 267.3 & 97 & 3 & - & - & 25 & 15 \\
\hline $\mathrm{F}_{12}$ & 342.2 & 570.3 & 73.1 & 2.9 & 24 & - & 25 & 13 \\
\hline
\end{tabular}

Figure 6: Process of production and purification of EM mixture.

\section{Conclusion}

Solar driven steam reforming of natural gas with two PSA unit to remove carbon dioxide seems a very interesting process to produce enriched methane mixture with $25 \%$ vol $\mathrm{H}_{2}$ which can be efficiently used in NG internal combustion engine. The process can operate with an almost complete hydrogen recovery and a methane recovery greater than $97 \%$. Using grid natural gas, the energy consumption is about $275 \mathrm{~kJ}$ per $\mathrm{kg}$ of produced hydromethane.

\section{References}

[1] Krajačić, G., Martins, R., Busuttil, A., Duić, N. \& Graça Carvalho, M., Hydrogen as an energy vector in the islands' energy supply. International Journal of Hydrogen Energy, 33, pp. 1091-1103, 2008. 
[2] Hetland, J. \& Mulder, G., In search of a sustainable hydrogen economy: How a large-scale transition to hydrogen may affect the primary energy demand and greenhouse gas emissions. International Journal of Hydrogen Energy, 32, pp. 736-747, 2007.

[3] Haeseldonckx, D. \& D'haeseleer, W., The use of natural-gas pipeline infrastructure for hydrogen transport in a changing market structure. International Journal of Hydrogen Energy, 32, pp. 1381-1386, 2007.

[4] Orhan Akansu, S., Dulger, Z., Kaharaman, N. \& Veziroglu, T., Internal combustion engines fuelled by natural gas-hydrogen mixtures. International Journal of Hydrogen Energy, 29, pp. 1527-1539, 2004.

[5] Ortenzi, F., Chiesa, M., Scarcelli, R. \& Pede, G., Experimental tests of blends of hydrogen and natural gas in light-duty vehicles. International Journal of Hydrogen Energy, 33, pp. 3225-3229, 2008.

[6] De Falco, M., Giaconia, A., Marrelli, L., Tarquini, P., Grena, R. \& Caputo, G., Enriched methane production using solar energy: an assessment of plant performance. International Journal of Hydrogen Energy, 34, pp. 98-109, 2009.

[7] De Falco, M., Caputo, G., Frattari, S., Gironi, F. \& Annesini, M., Solar steam reforming for enriched methane production: reactor configurations modeling and comparison. International Journal of Hydrogen Energy, 39, pp. 1397913990, 2014.

[8] Ruthven, D.M., Farooq, S. \& Knaebel, K., Pressure Swing Adsorption. VCH Publishers, Inc, 1994.

[9] Annesini, M., Augelletti, R., Gironi, F. \& Murmura, M., CO2 removal by pressure swing adsorption from $\mathrm{CO} 2-\mathrm{H} 2-\mathrm{CH} 4$ mixture produced by natural gas steam reforming at low temperature.

[10] Ahn, S., You, Y.W., Lee, D.G., Kim, K.H., Oh, M. \& Lee, C.H., Layered two- and four-bed PSA processes for $\mathrm{H} 2$ recovery from coal gas. Chemical Engineering Science, 68, pp. 413-423, 2012.

[11] Kapoor, A. \& Yang, T., Kinetic separation of methane-carbon dioxide mixture by adsorption on molecular sieve carbon. Chemical Engineering Science, 44, pp. 1723-1733, 1989. 